\title{
Assessment of the Thickness of the Roof of the Glenoid Fossa Using Cone Beam Computed Tomography in Asymptomatic Korean Adult Patients
}

\author{
Hyun-Jeong Park', Yo-Seob Seo², A-Hyang Yoon', Ji Hoo Kim', Ji-Won Ryu' \\ 'Department of Oral Medicine, School of Dentistry, Chosun University, Gwangju, Korea \\ ${ }^{2}$ Department of Oral and Maxillofacial Radiology, School of Dentistry, Chosun University, Gwangju, Korea
}

Received September 3, 2019

Revised September 4, 2019

Accepted September 4, 2019
Purpose: The aim of this study was to assess the thickness of the roof of the glenoid fossa (RGF) in Korean adult population without symptoms of temporomandibular disorder (TMD) using cone-beam computed tomography (CBCT).

Methods: CBCT Data from 111 Korean adult patients aged $\geq 25$ years (55 males and 56 females) without signs and symptoms of TMD were analyzed retrospectively in this study. The thickness of the RGF was determined as the perpendicular distance between the 'glenoid fossa line' and 'middle cranial fossa line' on parasagittal and paracoronal reconstructions, respectively. The thickness of the RGF according to sex and age was analyzed using t-tests $(p<0.05)$. Differences were also examined between the right and left sides, and between the paracoronal and parasagittal sides.

Results: The mean thickness of the RGF in all subjects was $0.75 \pm 0.39 \mathrm{~mm}$; there was no significant difference in thickness between male $(0.78 \pm 0.36 \mathrm{~mm})$ and female $(0.72 \pm 0.30 \mathrm{~mm})$. We found no correlation between age and the mean thickness of the RGF, when age was grouped by decade. However, when subjects were divided into $>40$ years and $\leq 40$ years age groups, the thickness of the RGF was significantly different between the groups.

Conclusions: We found that the thickness of the RGF did not differ by sex, but might be affected by aging. Further studies with larger numbers of subjects are needed to confirm the results of this study.

Key Words: Adult; Cone-beam computed tomography; Roof of glenoid fossa; Sex; Temporomandibular joint

\section{INTRODUCTION}

Temporomandibular disorders (TMDs) encompass a group of musculoskeletal and neuromuscular pathologic conditions that involve the temporomandibular joints (TMJs), the masticatory muscles, and all associated structures [1]. The TMJs consist of osseous components (condyle, glenoid fossa, and articular eminence) and soft tissues (articular disc and joint capsule) [2]. The glenoid fossa, located at the inferior aspect of the squamous part of temporal bone, is regarded as the temporal component of the TMJs [3].

Previous studies of TMJ osseous components have focused on the mandibular condyle, in terms of its relationship with the articular disc, its position in the joint cavity, and degenerative bone changes. However, the zygomatic bone and zygomatic process of the temporal bone together constitute an essential component of the masticatory apparatus, and are subjected to strains and stresses induced by masticatory muscles [4].

Although there is a lack of interest in the role of the

Copyright (c) 2019 Korean Academy of Orofacial Pain and Oral Medicine. All rights reserved.

(cc) This is an open-access article distributed under the terms of the Creative Commons Attribution Non-Commercial License (http://creativecommons.org/licenses/by-nc/4.0/), which permits unrestricted non-commercial use, distribution, and reproduction in any medium, provided the original work is properly cited. 
temporal bone in TMD, the thickness of the roof of the glenoid fossa (RGF) may be clinically significant in many respects. First, because of its proximity to vital structures, the bone thickness of the RGF is clinically relevant for TMJ surgeries and other procedures involving this area [5]. Second, sufficient thickness of the RGF is crucial to prevent dislocation of the mandibular condyle into the middle cranial fossa in cases of traumatic injury [6]. Finally, the thickness of the RGF could increase when the TMJ undergoes degenerative osteoarthritic changes, in addition to disc displacement or disc perforation [7].

To evaluate the relationship between degenerative bone changes and the thickness of the RGF, it is necessary to measure the thickness of the RGF in patients who do not exhibit arthritic changes. To the best of our knowledge, no studies have been conducted on the thickness of the RGF in Korean population.

Cone-beam computed tomography (CBCT) images are considered very useful for visualizing the TMJ, because of the need for a relatively low radiation dose but with high diagnostic quality [5]. Therefore, CBCT may be regarded as the imaging technique of choice for investigating bony changes of the TMJ [8]. The aim of this study was to assess the thickness of the RGF in Korean adult patients without symptoms of TMD using CBCT.

\section{MATERIALS AND METHODS}

\section{Subjects}

This retrospective study was approved by the Institutional Review Committee of the Chosun University Dental Hospital (CUDH) (IRB no. 1901/013). CBCT data from Korean adult patients aged $\geq 25$ years, obtained in preparation for third molar extraction, were retrospectively analyzed. These data were obtained from the archive of the Department of Oral and Maxillofacial Radiology, CUDH. Based on patients' medical records, those with a history of orthodontics, any signs or symptoms of TMD, a history of TMD treatment, and/or a history of local or systemic bone disease were excluded from the study. In addition, images were excluded if they showed degenerative bone changes in the mandibular condyle or the glenoid fossa, fractures (including of the mandible) that affected the condyle or its position, missing teeth in molar areas affecting the vertical dimension, and/ or were of poor quality. Demographic data (age and sex) were obtained and assessed in terms of their relationship with the thickness of the RGF. All data sets were acquired using the CS9300 3D CBCT device (Carestream Health Inc., Rochester, NY, USA) at CUDH. The following exposure parameters were used: tube potential, $85-90 \mathrm{kV}$; tube current, 4-5 mA; and field of view, $17 \times 13 \mathrm{~cm}$ with a $0.3-\mathrm{mm}$ voxel and $17 \times 11 \mathrm{~cm}$ with a $0.25-\mathrm{mm}$ voxel.

\section{Image Analysis}

Three-dimensional imaging software (OnDemand3D; CyberMed Co., Seoul, Korea) was used to prepare images of the glenoid fossa of the temporal bone. The images were reconstructed based on the individual angle of the condylar head. Paracoronal sections were obtained parallel to the horizontal axis of the condylar head, and parasagittal sections were reconstructed parallel to the line connecting the center point of the condylar head with the coronoid process, with 1-mm slice thickness and a 1-mm slice interval (Fig. 1). The reconstructed data sets were exported as Digital Imaging and Communications in Medicine image stacks.

\section{Measurement of the Thickness of the RGF}

Images of the central region of the glenoid fossa in parasagittal and paracoronal sections were used for the study

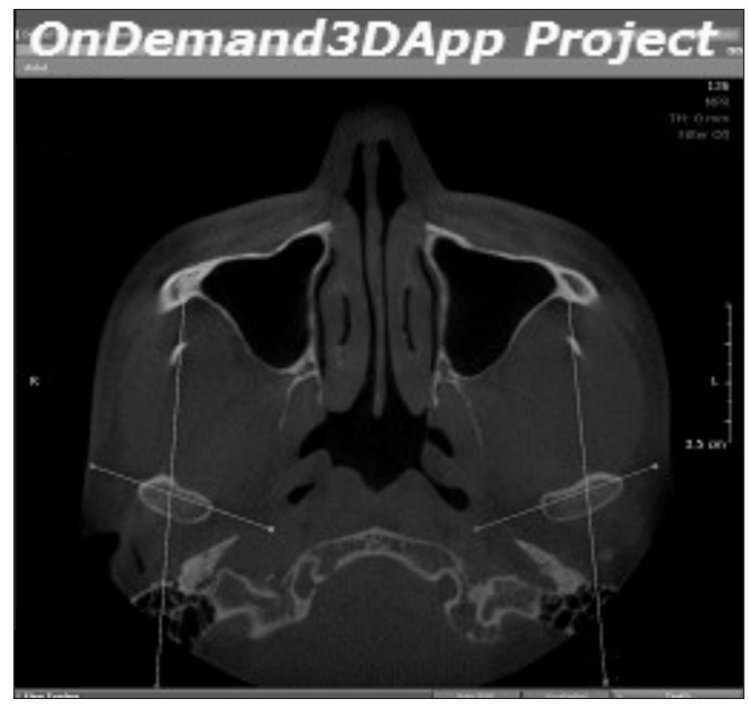

Fig. 1. Axial reconstruction of a cone beam computed tomography image. 
measurements in conjunction with the G3 image program (Infinitt Healthcare, Seoul, Korea). The images were assessed in a darkened room on a personal computer with a 32-inch LCD monitor. The contrast and brightness of the images were adjusted using the image processing tool included in the G3 software to ensure optimal visualization. The thickness of the RGF was determined as the perpendicular distance between the 'glenoid fossa line' and 'middle cranial fossa line' on parasagittal (Fig. 2) and paracoronal

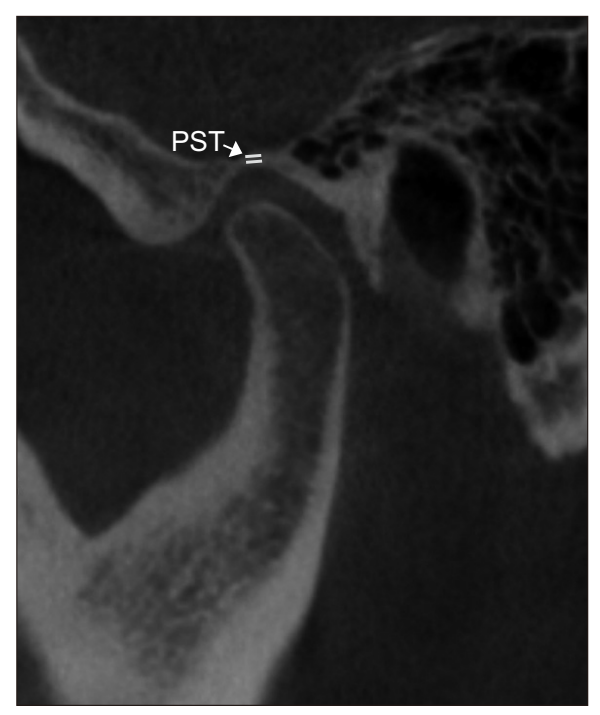

Fig. 2. Parasagittal reconstructions of cone beam computed tomography images. PST, parasagittal thickness of the roof of the glenoid fossa.

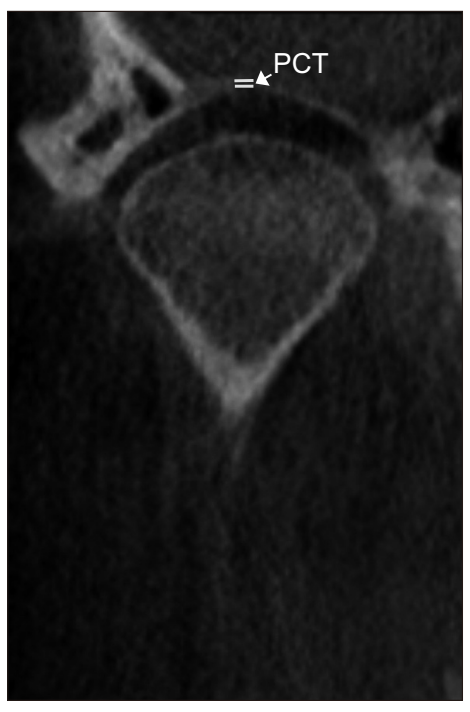

Fig. 3. Paracoronal reconstructions of cone beam computed tomography images. PCT, paracoronal thickness of the roof of the glenoid fossa. reconstructions (Fig. 3) [9].

Measurements of the thickness of the RGF were made three times by a single investigator (JR) at the thinnest part of the glenoid fossa, as identified on the monitor among multiple slices, and the mean value was calculated for statistical analysis [10]. Two weeks after the initial evaluation, $30 \%$ of the sample images were reassessed to determine the intra-examiner agreement. In addition, a reliability analysis was carried out using 10\% of the sample images, which were chosen at random. Measurements were performed by two clinicians (HP and JR), and the inter-examiner reliability was calculated.

\section{Statistical Analysis}

Statistical analyses were performed using IBM SPSS Statistics for Windows, Version 25.0 (IBM Co., Armonk, NY, USA). A p-value $<0.05$ was regarded as statistically significant. All quantitative variables are described as means \pm standard deviations. Intra- and inter-examiner agreement with respect to measure the RGF thickness was evaluated using the intraclass correlation coefficient (ICC). Analyses of the RGF thickness according to sex and age were performed using t-tests; the thickness was also compared between the right and left sides, and between the paracoronal and parasagittal sides.

\section{RESULTS}

Finally, 111 patients (55 male and 56 female; mean age, $33.66 \pm 8.19$ years) were included in the study. The clinical characteristics of the subjects are shown in Table 1. The ICCs for intra- and inter-examiner agreement were 0.975 and 0.947 , respectively $(\mathrm{p}<0.05)$, which denoted excellent reproducibility and reliability with respect to measurement

Table 1. Demographic characteristics of the subjects

\begin{tabular}{ccc}
\hline Age group & Male & Female \\
\hline Age $(y)$ & & \\
$25-30 y$ & 20 & 29 \\
$31-40$ y & 21 & 20 \\
$41-50 y$ & 11 & 5 \\
$>51$ y & 3 & 2 \\
Total & 55 & 56 \\
\hline
\end{tabular}

Values are presented as number only. 
Table 2. The mean thickness of the roof of the glenoid fossa according to sex

\begin{tabular}{lccccc}
\hline Sex & Rt. Paracoronal $(\mathrm{mm})$ & Lt. paracoronal $(\mathrm{mm})$ & Rt. Parasagittal $(\mathrm{mm})$ & Lt. parasagittal $(\mathrm{mm})$ & Total $(\mathrm{mm})$ \\
\hline Male & $0.76 \pm 0.37$ & $0.82 \pm 0.41$ & $0.76 \pm 0.31$ & $0.80 \pm 0.48$ & $0.78 \pm 0.36$ \\
Female & $0.73 \pm 0.31$ & $0.69 \pm 0.40$ & $0.71 \pm 0.32$ & $0.73 \pm 0.28$ \\
Total & $0.74 \pm 0.34$ & $0.78 \pm 0.47$ & $0.73 \pm 0.31$ & $0.76 \pm 0.39$ & $0.72 \pm 0.30$ \\
\hline
\end{tabular}

Rt, right; Lt, left.

Values are presented as mean \pm standard deviation.

$\mathrm{p}>0.05$, t-test.

Table 3. The mean thickness of the roof of the glenoid fossa according to age

\begin{tabular}{cccccc}
\hline Age group & Rt. Paracoronal $(\mathrm{mm})$ & Lt. paracoronal $(\mathrm{mm})$ & Rt. Parasagittal $(\mathrm{mm})$ & Lt. parasagittal $(\mathrm{mm})$ & Total $(\mathrm{mm})$ \\
\hline $25-30 \mathrm{y}$ & $0.75 \pm 0.33$ & $0.80 \pm 0.39$ & $0.73 \pm 0.35$ & $0.81 \pm 0.41$ & $0.77 \pm 0.37$ \\
$31-40 \mathrm{y}$ & $0.69 \pm 0.24$ & $0.69 \pm 0.33$ & $0.69 \pm 0.23$ & $0.65 \pm 0.18$ & $0.68 \pm 0.24$ \\
$41-50 \mathrm{y}$ & $0.85 \pm 0.31$ & $0.81 \pm 0.38$ & $0.84 \pm 0.34$ & $0.79 \pm 0.27$ \\
$>51 \mathrm{y}$ & $0.78 \pm 0.40$ & $1.10 \pm 0.54$ & $0.79 \pm 0.44$ & $1.26 \pm 0.70$ & $0.82 \pm 0.32$ \\
\hline
\end{tabular}

Rt, right; Lt, left.

Values are presented as mean \pm standard deviation.

p $>0.05$, t-test.

Table 4. The mean thickness of the RGF according to revised age groups

\begin{tabular}{ccc}
\hline Age group & Total RGF thickness $(\mathrm{mm})$ & p-value \\
\hline$\leq 40 \mathrm{y}$ & $0.73 \pm 0.32$ & $0.011^{\mathrm{a}}$ \\
$>40 \mathrm{y}$ & $0.86 \pm 0.37$ & \\
\hline
\end{tabular}

RGF, roof of the glenoid fossa.

Values are presented as mean \pm standard deviation.

${ }^{a} p<0.05$, t-test.

of the thickness of the RGF.

The mean thickness values of the RGF according to sex are shown in Table 2. The mean thickness of the RGF in all subjects was $0.75 \pm 0.39 \mathrm{~mm}$. The mean thickness of the RGF for male and female was $0.78 \pm 0.36 \mathrm{~mm}$ and $0.72 \pm 0.30 \mathrm{~mm}$, respectively. There was no significant difference in the RGF thickness between sex ( $p>0.05$, t-test). We also compared the mean RGF thickness between the parasagittal and paracoronal reconstruction images; these did not show a statistically significant difference. The mean thickness of the RGF was greater on the left side $(0.77 \pm 0.44 \mathrm{~mm})$ than on the right side $(0.74 \pm 0.33 \mathrm{~mm})$, but the difference was not statistically significant.

To assess the relationship between age and the RGF thickness, subject age was stratified by decade (Table 3). Overall, the RGF thickness did not differ significantly according to age. However, the mean thickness of the RGF measured on right paracoronal images was significantly different between patients aged 31-40 years versus those aged 41-50 years. In addition, the thickness measured on left parasagittal images was significantly different between patients aged 21-30 years versus those aged over 51 years. Therefore, the subjects were regrouped based on a cutoff age of 40 years (Table 4); the two groups showed a statistically significant difference in RGF thickness.

\section{DISCUSSION}

In this study, the mean thickness of the RGF in asymptomatic Korean adults was $0.75 \mathrm{~mm}(0.75 \mathrm{~mm}$ for male and $0.72 \mathrm{~mm}$ for female). These findings are similar to those of a Japanese autopsy study [11]. In contrast, the mean thickness was $0.97 \mathrm{~mm}$ for Europeans [10] and $1.12 \mathrm{~mm}$ for Iranians [12]. Although the mean thickness of the RGF is known to vary from 0.5 to $1.5 \mathrm{~mm}$ [13], these variations could be due to age differences among subjects. In the present study, adults aged $\geq 25$ years were selected as the study group. In contrast, the European and Iranian studies included children or adolescents, as well as adults. We enrolled adults aged $\geq 25$ years because mandibular height growth is known to be completed after 20 years of age [14]. Although the growth of the temporal bone, including the articular eminence, is morphologically complete around puberty [15], the mandibular condyle and glenoid fossa can 
show functional adaptation in response to environmental changes [16]. However, such findings may be influenced by anthropological differences; future investigations should clarify whether other factors, such as ethnicity and patterns of growth and development, influence the anatomy of the glenoid fossa and mandibular condyle.

In the present study, there was no significant correlation between sex and the RGF thickness, consistent with previous studies [3,10-12]. There have been several studies on the relationship between sex and the RGF thickness, but only one paper has compared the thickness of the RGF between the right and left sides [17]; that study showed a difference in RGF thickness between sides. The authors presumed that this asymmetry could be related to cranial base asymmetry [17]. In our study, the thickness of the RGF was greater on the left side than on the right side, but the difference was not statistically significant. However, neither the present study nor the prior study performed any metrological analysis of cranial base asymmetry. Therefore, further research should be conducted.

On comparing the mean thickness of the RGF between parasagittal and paracoronal images, we found that there was no statistically significant difference. This suggests that the image reconstruction method used in this study was reliable for measuring the thickness of the RGF.

We divided the subjects into 10-year age groups (except for those in their 20s, as the subjects were all adults aged $\geq 25$ years). We found no correlation between age and the mean thickness of the RGF. In the previous studies mentioned above [3,10-12,17], there were no correlations between age and RGF thickness. However, our study found that RGF thickness differed significantly between the subjects aged $>40$ years versus $\leq 40$ years. These results suggest that the glenoid fossa changes with age. Although the changes with age seen in the mandibular condyle are more prominent than those seen in the glenoid fossa, the glenoid fossa shows marked responsiveness to environmental changes [18]. The glenoid fossa might undergo remodeling in response to changes in articular dynamics associated with functional biomechanical behavior, and according to dysfunction or disuse [19]. Degenerative changes in the mandibular condyle may occur after 40 years of age even in the absence of symptoms [20]. Therefore, subsequent studies should compare the thickness of the RGF between patients with symptoms and signs of jaw joint disease and asymptomatic patients.

In conclusion, we assessed the thickness of the RGF in Korean adult patients without symptoms of TMD using СВCT. We found that the thickness of the RGF did not differ by sex, but environmental changes aging might affect the RGF thickness. Further studies including larger numbers of subjects are needed to confirm the results of this study.

\section{CONFLICT OF INTEREST}

No potential conflict of interest relevant to this article was reported.

\section{ORCID}

\author{
Hyun-Jeong Park \\ https://orcid.org/0000-0002-5237-005X \\ Yo-Seob Seo \\ https://orcid.org/0000-0003-1804-5648 \\ A-Hyang Yoon \\ https://orcid.org/0000-0002-4588-0692 \\ Ji Hoo Kim \\ https://orcid.org/0000-0002-0669-3309 \\ Ji-Won Ryu \\ https://orcid.org/0000-0002-5586-8195
}

\section{REFERENCES}

1. de Leeuw R, Klasser GD. Orofacial pain: guidelines for assessment, diagnosis, and management. 6th ed. Hanover Park, IL: Quintessence; 2018. p. 144-207.

2. Lobo F, Tolentino ES, Iwaki LCV, Walewski LÂ, Takeshita WM, Chicarelli M. Imaginology tridimensional study of temporomandibular joint osseous components according to sagittal skeletal relationship, sex, and age. J Craniofac Surg 2019;30:1462-1465.

3. İlgüy D, İlgüy M, Fişekçioğlu E, Dölekoğlu S, Ersan N. Articular eminence inclination, height, and condyle morphology on cone beam computed tomography. ScientificWorldJournal 2014. doi:10.1155/2014/761714.

4. Buyuk C, Gunduz K, Avsever H. Prevalence and characteristics of pneumatizations of the articular eminence and roof of the glenoid fossa on cone-beam computed tomography. Oral Radiol 2019;35:171-176.

5. Soydan D, Doğan S, Canger EM, Coşgunarslan A, Akgün IE, Kış HC. Effect of internal derangements and degenerative bone 
changes on the minimum thickness of the roof of the glenoid fossa in temporomandibular joint. Oral Radiol 2019. doi: 10.1007/ s11282-019-00373-6. [Epub ahead of print]

6. Koretsch LJ, Brook AL, Kader A, Eisig SB. Traumatic dislocation of the mandibular condyle into the middle cranial fossa: report of a case, review of the literature, and a proposal management protocol. J Oral Maxillofac Surg 2001;59:88-94.

7. Honda K, Larheim TA, Sano T, Hashimoto K, Shinoda K, Westesson PL. Thickening of the glenoid fossa in osteoarthritis of the temporomandibular joint. An autopsy study. Dentomaxillofac Radiol 2001;30:10-13.

8. Tsiklakis K, Syriopoulos K, Stamatakis HC. Radiographic examination of the temporomandibular joint using cone beam computed tomography. Dentomaxillofac Radiol 2004;33:196-201.

9. Nadaes MR, Lagos de Melo LP, Haiter Neto F, Freitas DQ. Correlation between temporomandibular joint temporal component pneumatization and morphology: analysis by cone beam computed tomography. Int J Oral Maxillofac Surg 2019;48:779-786.

10. Ejima K, Schulze D, Stippig A, Matsumoto K, Rottke D, Honda K. Relationship between the thickness of the roof of glenoid fossa, condyle morphology and remaining teeth in asymptomatic European patients based on cone beam CT data sets. Dentomaxillofac Radiol 2013. doi:10.1259/dmfr/90929410.

11. Honda K, Kawashima S, Kashima M, Sawada K, Shinoda K, Sugisaki M. Relationship between sex, age, and the minimum thickness of the roof of the glenoid fossa in normal temporomandibular joints. Clin Anat 2005;18:23-26.
12. Khojastepour L, Haghnegahdar A, Eisazadeh M, Bahreini M. Comparison between glenoid fossa roof thickness in TMD and non-TMD patients, a CBCT study. J Dent Shiraz Univ Med Sci 2019;20:165-170.

13. Greene MW, Hackney FL, Van Sickels JE. Arthroscopy of the temporomandibular joint: an anatomic perspective. J Oral Maxillofac Surg 1989;47:386-389.

14. Howard JA. Temporomandibular joint disorders in children. Dent Clin North Am 2013;57:99-127.

15. Bender ME, Lipin RB, Goudy SL. Development of the pediatric temporomandibular joint. Oral Maxillofac Surg Clin North Am 2018;30:1-9.

16. Owtad P, Park JH, Shen G, Potres Z, Darendeliler MA. The biology of TMJ growth modification: a review. J Dent Res 2013;92:315321.

17. Al-koshab M, Nambiar P, John J. Assessment of condyle and glenoid fossa morphology using CBCT in South-East Asians. PLoS One 2015;10:e0121682.

18. Owtad P, Potres Z, Shen G, Petocz P, Darendeliler MA. A histochemical study on condylar cartilage and glenoid fossa during mandibular advancement. Angle Orthod 2011;81:270-276.

19. Jain A, Thenmozhi MS. A study on morphology and morphometry of mandibular fossa. Drug Invent Today 2018;10:2289-2292.

20. Caruso S, Storti E, Nota A, Ehsani S, Gatto R. Temporomandibular joint anatomy assessed by CBCT images. Biomed Res Int 2017. doi: $10.1155 / 2017 / 2916953$. 